\title{
All-Polymer Solar Cells Based on Fully Conjugated Donor-Acceptor Block Copolymers with Poly(naphthalene bisimide) Acceptor Blocks: Device Performance and Thin Film Morphology
}

\author{
Kazuhiro Nakabayashi and Hideharu Mori \\ Department of Polymer Science and Engineering, Graduate School of Science and Engineering, Yamagata University,
} 4-3-16 Jonan, Yonezawa 992-8510, Japan

Correspondence should be addressed to Kazuhiro Nakabayashi; nakabayashi.k@yz.yamagata-u.ac.jp

Received 29 August 2014; Revised 24 October 2014; Accepted 29 October 2014

Academic Editor: Shimou Chen

Copyright (C) 2015 K. Nakabayashi and H. Mori. This is an open access article distributed under the Creative Commons Attribution License, which permits unrestricted use, distribution, and reproduction in any medium, provided the original work is properly cited.

\begin{abstract}
All-polymer solar cells are fabricated by using poly(3-hexylthiophene) (P3HT) and fully conjugated donor-acceptor (D-A) block copolymer (P3HT-PNBI-P3HT) as donor and acceptor materials, respectively. Atomic force microscopy (AFM) and grazing incidence wide angle X-ray scattering (GIWAXS) analyses reveal that device performance strongly depends on the P3HT:P3HTPNBI-P3HT thin film morphology. Indeed, the $\pi-\pi$ stacking nanomorphology rich in the edge-on orientation is formed in the P3HT:P3HT-PNBI-P3HT thin film by optimizing the fabrication conditions, for example, thermal annealing temperature and cast solvent. Consequently, the power conversion efficiency (PCE) of $1.60 \%$ is achieved with an open-circuit voltage $\left(V_{\mathrm{oc}}\right)$ of $0.59 \mathrm{~V}$, short-current $\left(J_{\mathrm{sc}}\right)$ of $4.43 \mathrm{~mA} / \mathrm{cm}^{2}$, and fill factor $(\mathrm{FF})$ of 0.61 . These results suggest that P3HT-PNBI-P3HT has the huge potential for the usage as a nonfullerene acceptor material.
\end{abstract}

\section{Introduction}

Over the last decade, polymer/fullerene organic solar cells (OSCs), in which active layers are composed of polymeric donor and fullerene-based acceptor materials, have been extensively investigated as revolutionary renewable energy sources because of their advantages (e.g., low cost, light weight, flexibility, and facile large scale fabrication) compared to silicon-based solar cells [1-4]. To date, PCEs of around $10 \%$ have been achieved in OSCs [5], mainly through the development of various specialized polymeric donor materials (e.g., low bandgap polymers). However, acceptor materials are, compared to donor materials, far less developed, and the fullerene derivative, $[6,6]$-phenyl $\mathrm{C}_{61}$ butyric acid methyl ester (PCBM), is the only conventional acceptor material for OSCs. One of the major reasons using PCBM as an acceptor material in OSCs is its high electron mobility (ca. $0.002 \mathrm{~cm}^{2} / \mathrm{V} \cdot \mathrm{s}$ ) [6]. On the other hand, there are considerable drawbacks for the use of PCBM in OSCs: (i) negligible light absorption in the visible-near IR regions, (ii) relatively poor photochemical and chemical stability, (iii) low miscibility with donor polymeric materials, and (iv) high cost for synthesis and purification. In recent years, high-performance OSCs, which depend on the development of polymeric donor materials, have reached a critical limit. To resolve the current situation, novel acceptor materials other than fullerene-based materials are necessary; in this regard, polymer/polymer OSCs based on nonfullerene polymeric acceptor materials, the so-called all-polymer solar cells, are receiving increased attention [7-12]. Regardless of such attention, the PCEs of all-polymer solar cells reported in many previous studied are quite low compared to fullerene-based OSCs [13-15]. Thus, further development of specialized acceptor materials for OSCs is imperative for realizing high-performance all-polymer solar cells. For example, arylene bisimidebased, for example, naphthalene bisimide (NBI) and perylene 
bisimide-based, acceptor materials are considered to be promising candidates because of their high stability, excellent acceptor properties due to well-placed LUMO levels, and high electron mobilities [16-23]. Indeed, several all-polymer solar cells based on those acceptor materials accomplished excellent PCEs (2-4\%) [20-24].

In previous work, we developed a novel fully conjugated D-A block copolymer with NBI-based acceptor blocks (P3HT-PNBI-P3HT) for a nonfullerene acceptor material [16]. The fusion of the fully conjugated D-A structure and NBI-based acceptor blocks provided ideal characteristics for OSC acceptor materials, that is, broad light absorption, favorable LUMO level, good miscibility with P3HT, and so on. Furthermore, the all-polymer solar cell with the P3HT:P3HTPNBI-P3HT blend active layer achieved a PCE over $1.0 \%$. The previous work is the first example of the use of fully conjugated D-A block copolymers as acceptor materials for all-polymer solar cells, and the obtained device performances demonstrated that the fully conjugated D-A block copolymer, P3HT-PNBI-P3HT, had a potential to serve as a nonfullerene acceptor material.

Toward the higher performance of all-polymer solar cells based on fully conjugated D-A block copolymers, we herein investigated the in-depth relationship between device performance and thin film morphology in the P3HT:P3HTPNBI-P3HT blend active layer by a combination of AFM and GIWAXS analyses. By optimizing the device fabrication conditions, the P3HT:P3HT-PNBI-P3HT blend active layer with $\pi-\pi$ stacking nanostructure could be prepared, and a PCE as high as $1.60 \%$ was achieved.

\section{Experimental}

2.1. Materials. Fully conjugated D-A block copolymers (P3HTPNBI-P3HT) were synthesized according to the previous literature [17]. Poly(3-hexylthiophene) (regioregularity $=91-$ $\left.94 \%, M_{w}=50000-70000\right)$ was purchased from Rieke Metals, Inc.

\subsection{All-Polymer Solar Cell Fabrication and Measurements.} The typical procedure of ITO/PEDOT:PSS/P3HT:P3HT$\mathrm{PNBI}-\mathrm{P} 3 \mathrm{HT} / \mathrm{Ca} / \mathrm{Al}$ architecture is as follows: commercially available prepatterned $15 \Omega / \square$ sheet resistance indium tin oxide (ITO) substrates $(2.0 \mathrm{~cm} \times 1.5 \mathrm{~cm})$ were cleaned and plasma-etched. Then poly(3,4-ethylenedioxythiophene):poly(styrenesulfonate) (PEDOT:PSS) aqueous solution (Clevios P VP AI 4083) was spin-coated at $4000 \mathrm{rpm}$ for $40 \mathrm{~s}$ and subsequently annealed under flowing nitrogen at $120^{\circ} \mathrm{C}$ for $10 \mathrm{~min}$. Substrates were allowed to cool under nitrogen atmosphere and then transferred to a glovebox. P3HT:P3HTPNBI-P3HT blend chlorobenzene solution was spin-coated at $700 \mathrm{rpm}$ for $90 \mathrm{~s}$, and the active layer was annealed for $15 \mathrm{~min}$. The blend solution that $5 \mathrm{mg}$ of each polymer dissolved in $1 \mathrm{~mL}$ of chlorobenzene (1:1 by weight, conc. = $10 \mathrm{mg} / \mathrm{mL}$ ) was prepared in a glovebox. Then the top electrode consisted of $\mathrm{Ca}$ interlayer $(20 \mathrm{~nm})$ and $\mathrm{Al}$ electrode $(80 \mathrm{~nm})$ was vacuum-deposited. The $J-V$ characteristics of the devices were measured by using a direct-current voltage and a current source/monitor (Bunko-Keiki, BSO-X500L) in nitrogen atmosphere under AM1.5G simulated solar light at $100 \mathrm{~mW} / \mathrm{cm}^{2}$. The light intensity was corrected with a calibrated silicon photodiode reference cell (Bunko-Keiki, BS-520).

\section{Results and Discussion}

3.1. Performance of All-Polymer Solar Cells with P3HT-PNBIP3HT. All-polymer solar cells with the P3HT:P3HT-PNBI$\mathrm{P} 3 \mathrm{HT}$ blend active layers were fabricated by using $\mathrm{P} 3 \mathrm{HT}-$ PNBI-P3HTs with different molecular weights and compositions of each block (P1 and P2, see Figure 1(a) for details). The device architecture is as follows: ITO/PEDOT:PSS/ P3HT:P3HT-PNBI-P3HT (1:1 by weight)/Ca/Al. The device performances are summarized in Table 1 . In the P3HT:P1 system, a PCE of $0.50 \%$ with $V_{\text {oc }}$ of $0.51 \mathrm{~V}, J_{\text {sc }}$ of $2.12 \mathrm{~mA} / \mathrm{cm}^{2}$, and FF of 0.47 was obtained without thermal annealing. The PCE gradually improved with an increase in the thermal annealing temperature and finally reached $1.20 \%$ with $V_{\text {oc }}$ of $0.59 \mathrm{~V}, J_{\mathrm{sc}}$ of $3.28 \mathrm{~mA} / \mathrm{cm}^{2}$, and FF of 0.62 when annealed at $200^{\circ} \mathrm{C}$ (Figure 2(a)). In the P3HT:P2 system, the high PCE of $1.28 \%$ was also obtained with thermal annealing at $200^{\circ} \mathrm{C}\left(V_{\text {oc }}\right.$ of $0.56 \mathrm{~V}, J_{\text {sc }}$ of $4.57 \mathrm{~mA} / \mathrm{cm}^{2}$, and $\mathrm{FF}$ of 0.50$)$. Furthermore, the best PCE of $1.60 \%$ was achieved when using dichlorobenzene (DCB) instead of chlorobenzene (CB) as the cast solvent (Table 1 in Entry 7 and Figure 2(b)). This PCE improvement was attributed to two factors: (1) enhanced light absorption of the P3HT:P3HT-PNBI-P3HT blend film due to thermal annealing (Figure 1(b)) and (2) a significant increase in $J_{\mathrm{sc}}$ values. Considering that $J_{\mathrm{sc}}$ values are closely related to the thin film morphology with nanoscale, thermal annealing and the cast solvent should lead to morphological changes in the blend active layer, as discussed in many previous works, resulting in the improvement of PCEs $[25,26]$.

For comparison with the P3HT:P3HT-PNBI-P3HT system, the performance of an all-polymer solar cells with the P3HT:PNBI blend active layer was then evaluated; consequently, the PCE of that cell was $0.49 \%$ (the PCE of the P3HT:P3HT-PNBI-P3HT system was $1.60 \%$ under the same conditions). Considering that the optical and electrochemical properties of PNBI were almost same as those of P3HTPNBI-P3HT, the other factor such as the nanomorphology in the P3HT:PNBI blend active layer might cause the quite lower device performance compared to that of the P3HT:P3HTPNBI-P3HT system (see Figure 3(d) and Figure S1 in Supplementary Material available online at http://dx.doi.org/ $10.1155 / 2014 / 826985$ for details).

3.2. Nanomorphology Observation by AFM Measurement. To understand the difference in the device performance, the surface morphology of the P3HT:P3HT-PNBI-P3HT blend films was investigated by AFM measurements. As depicted in Figures 3(a)-3(c), no significant differences in the sizes of the bright and dark domains were found, regardless of the thermal annealing and cast solvent conditions, whereas the average root-mean-square ( $\mathrm{rms}$ ) roughness tended to be largely dependent on the fabrication conditions. The device 


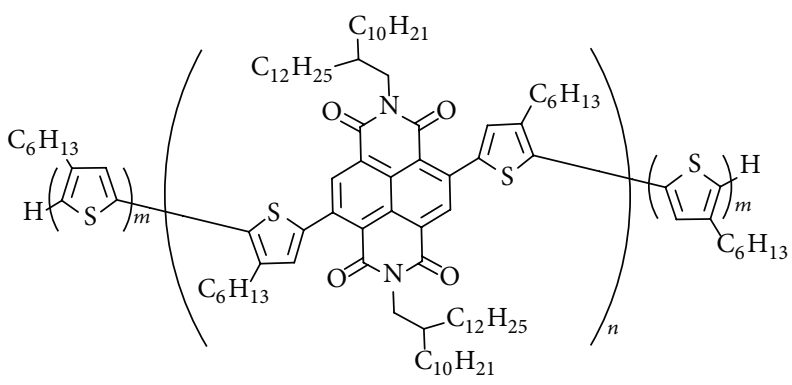

P1: $M_{n}=21800, M_{w} / M_{n}=1.28$

$(m / n / m=28 / 8 / 28)$

P2: $M_{n}=26000, M_{w} / M_{n}=1.60$

$(m / n / m=19 / 9 / 19)$

(a)

FIgURE 1: (a) Structural information of P3HT-PNBI-P3HT and (b) UV-vis absorption spectra of the P3HT:P1 blend film. The thermal annealing was carried out under nitrogen atmosphere for $30 \mathrm{~min}$.

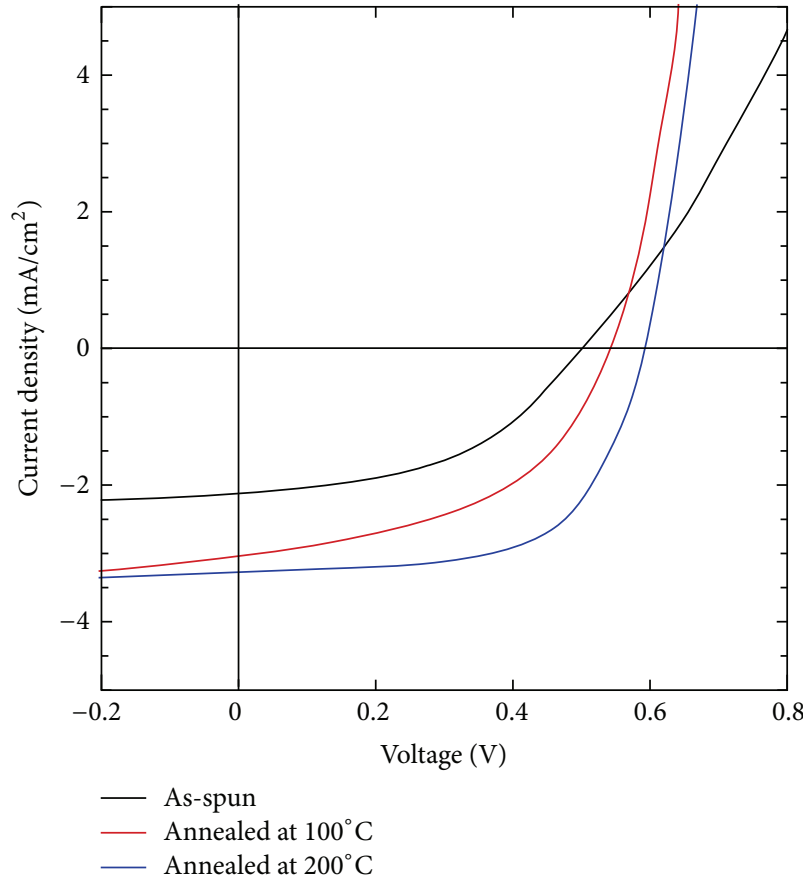

(a)

- Annealed at $100^{\circ} \mathrm{C}$

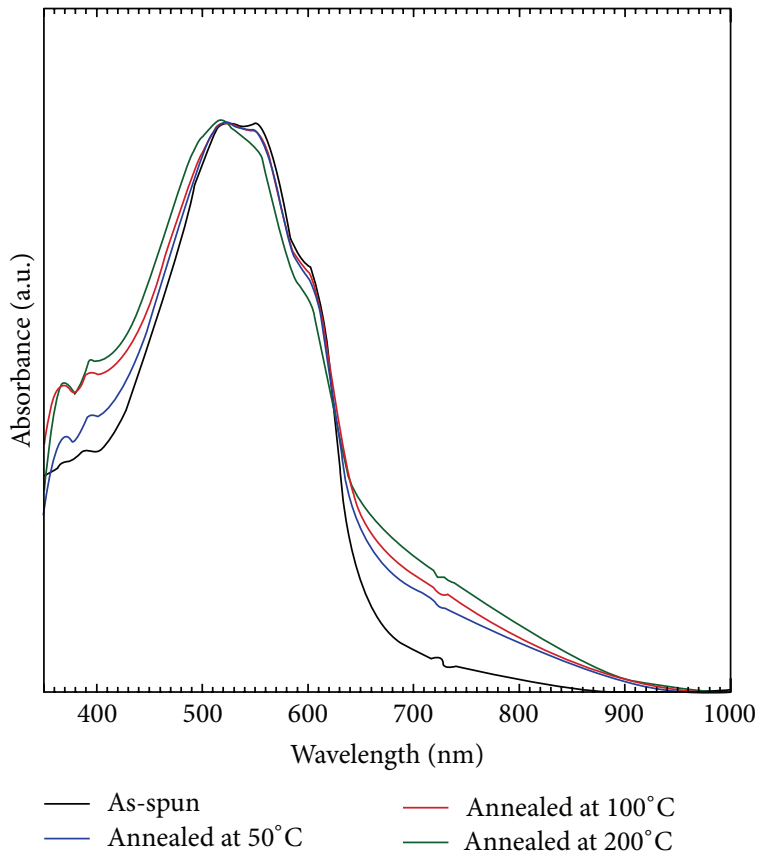

(b)

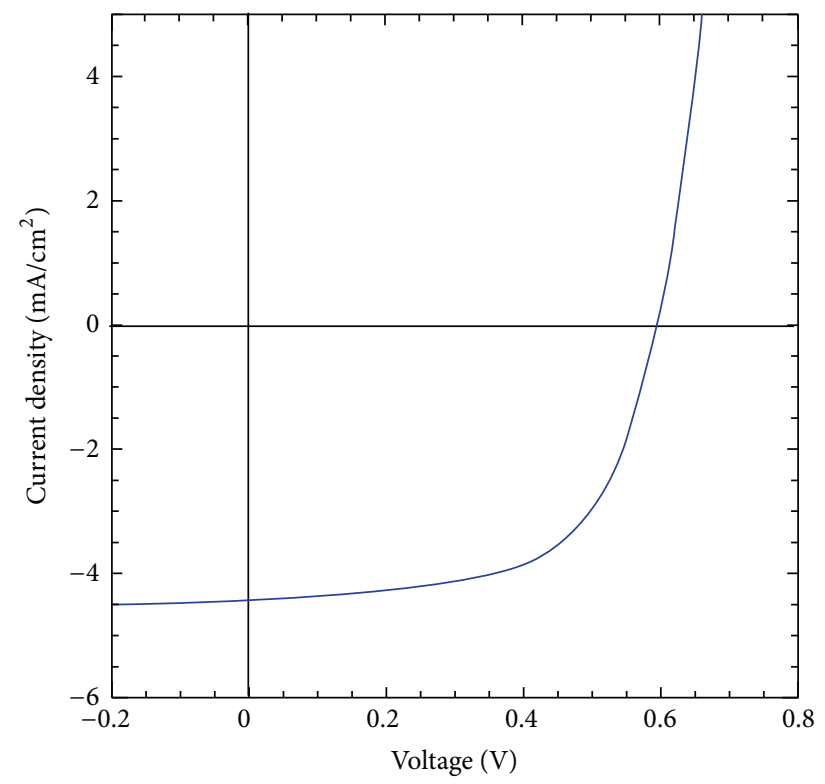

(b)

Figure 2: $J-V$ characteristics of (a) P3HT:P1 system and (b) highest-performance device with P3HT:P2 system under AM1.5G (100 mW/ $\mathrm{cm}^{2}$ ) illumination. 
TABLE 1: Results of device performance.

\begin{tabular}{|c|c|c|c|c|c|c|}
\hline Entry & Compositions $^{\mathrm{a}}$ & $\begin{array}{c}\text { Conditions } \\
\text { (solvent/annealing temperature) }^{\mathrm{b}, \mathrm{c}}\end{array}$ & $V_{\mathrm{oc}}(\mathrm{V})$ & $J_{\mathrm{sc}}\left(\mathrm{mA} / \mathrm{cm}^{2}\right)$ & $\mathrm{FF}$ & $\operatorname{PCE}(\%)^{\mathrm{d}}$ \\
\hline 1 & P3HT:P1 & $\mathrm{CB} / \mathrm{as}$-spun & 0.51 & 2.12 & 0.47 & 0.50 \\
\hline 2 & & $\mathrm{CB} / 100^{\circ} \mathrm{C}$ & 0.54 & 3.03 & 0.48 & 0.79 \\
\hline 3 & & $\mathrm{CB} / 200^{\circ} \mathrm{C}$ & 0.59 & 3.28 & 0.62 & 1.20 \\
\hline 4 & P3HT:P2 & $\mathrm{CB} / \mathrm{as}$-spun & 0.49 & 1.60 & 0.47 & 0.37 \\
\hline 5 & & $\mathrm{CB} / 100^{\circ} \mathrm{C}$ & 0.53 & 3.53 & 0.39 & 0.74 \\
\hline 6 & & $\mathrm{CB} / 200^{\circ} \mathrm{C}$ & 0.56 & 4.57 & 0.50 & 1.28 \\
\hline 7 & & $\mathrm{DCB} / 200^{\circ} \mathrm{C}$ & 0.59 & 4.43 & 0.61 & 1.60 \\
\hline
\end{tabular}

${ }^{\mathrm{a}} 1: 1$ by weight. ${ }^{\mathrm{b}} \mathrm{CB}$ : chlorobenzene; DCB: $o$-dichlorobenzene. ${ }^{\mathrm{c}}$ Thermal annealing was carried out under nitrogen atmosphere for 30 minutes. ${ }^{\mathrm{d}}$ Average values of eight devices.

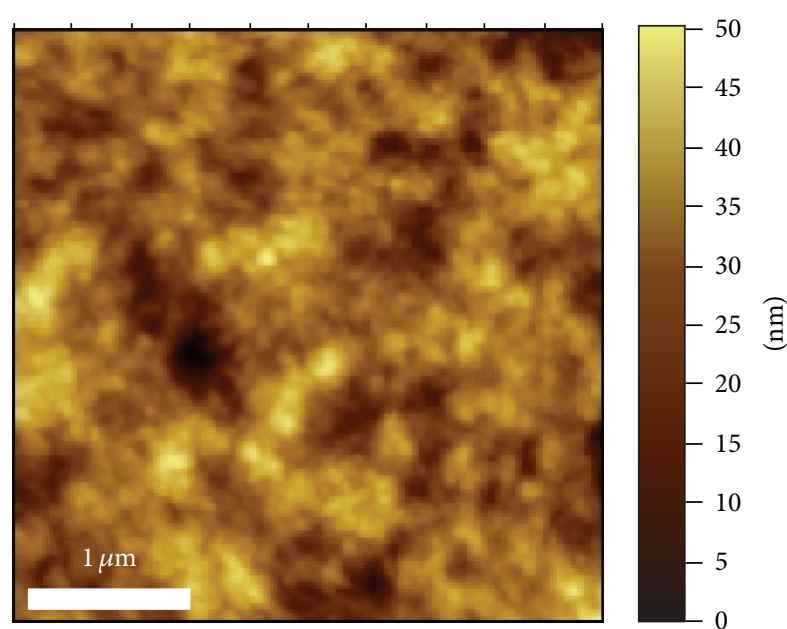

(a) $\mathrm{rms}=6.90 \mathrm{~nm}$

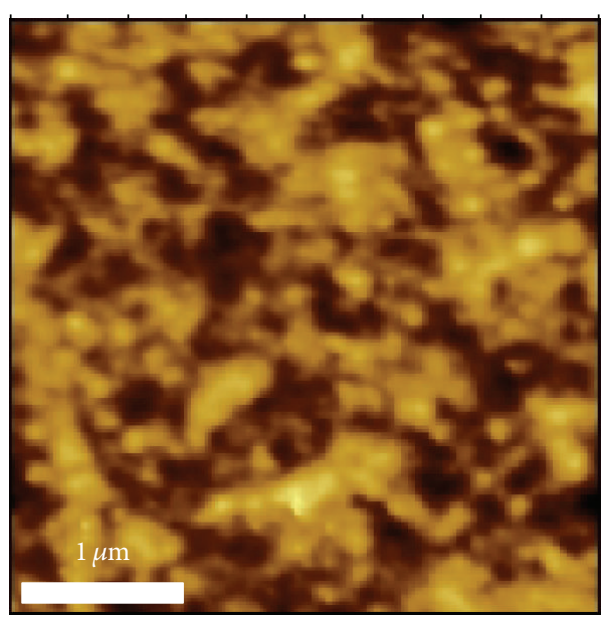

(c) $\mathrm{rms}=2.53 \mathrm{~nm}$

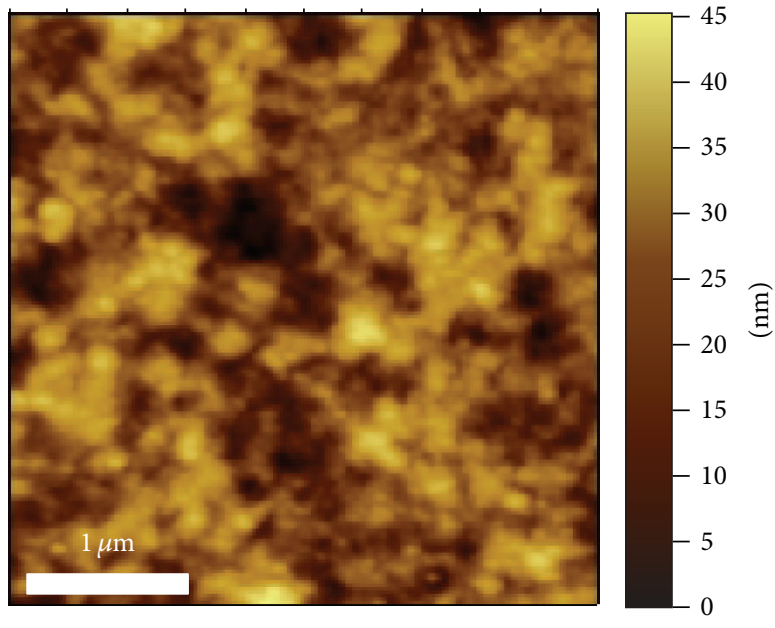

(b) $\mathrm{rms}=6.23 \mathrm{~nm}$

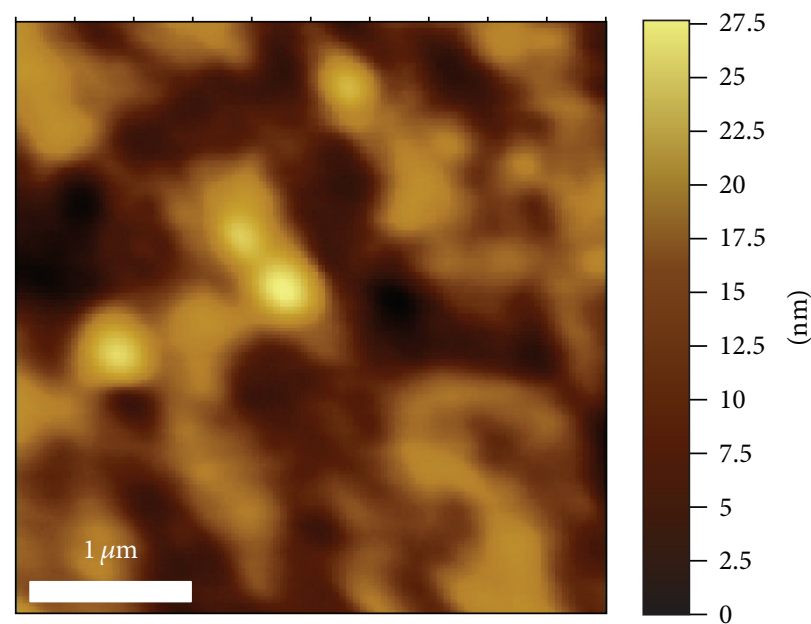

(d) $\mathrm{rms}=3.12 \mathrm{~nm}$

Figure 3: AFM height images of P3HT:P2 ((a) Entry 4, (b) Entry 6, and (c) Entry 7 in Table 1) and (d) P3HT:PNBI blend thin films (3 $\mu \mathrm{m} \times$ $3 \mu \mathrm{m})$.

with a low PCE (PCE $=0.73 \%$, Entry 4 in Table 1$)$ exhibited a relatively large $\mathrm{rms}$ roughness $(6.90 \mathrm{~nm})$, and in contrast, the highest-performance device ( $\mathrm{PCE}=1.60 \%$, Entry 7 in Table 1$)$ exhibited the smallest $\mathrm{rms}$ roughness $(2.53 \mathrm{~nm})$. Even though the nanomorphology inside the active layer is the most important factor when discussing device performance [2628], the AFM analysis indicated that there was a clear relationship between device performance and surface roughness. As for the P3HT:PNBI blend film (Figure 3(d)), phase separation was quite larger due to the aggregation of NBI 


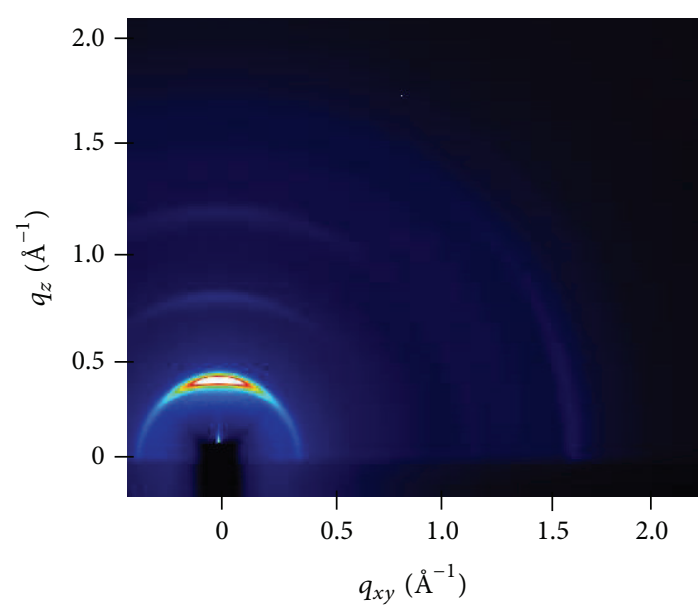

(a) $\mathrm{PCE}=0.37 \%$

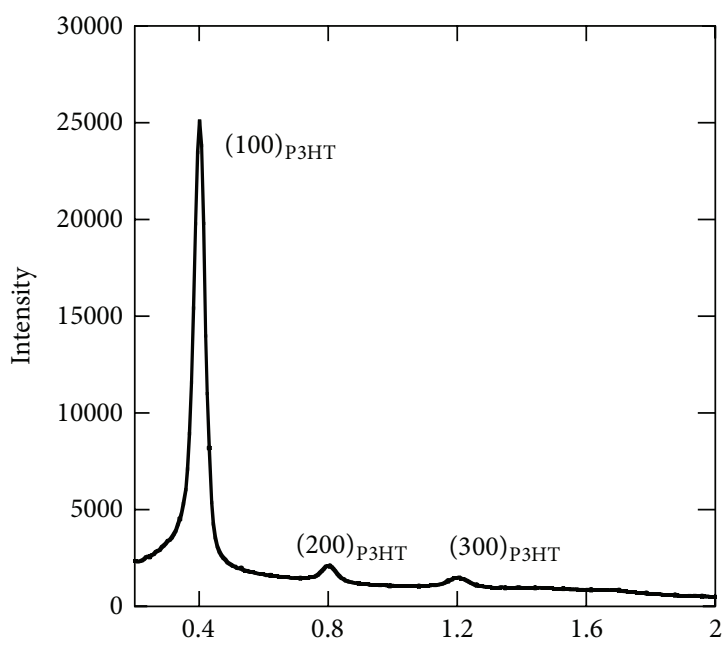

$q_{z}\left(\AA^{-1}\right)$

(b) Out-of-plane

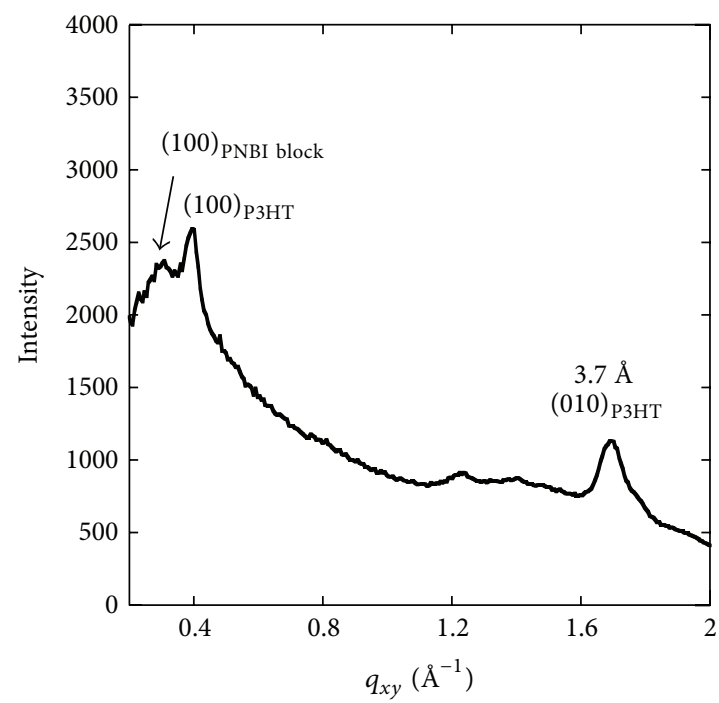

(c) In-plane

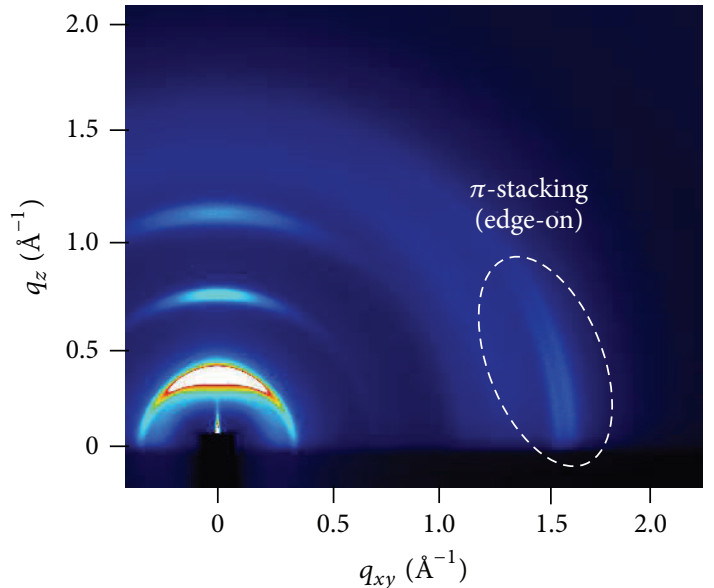

(d) $\mathrm{PCE}=1.60 \%$

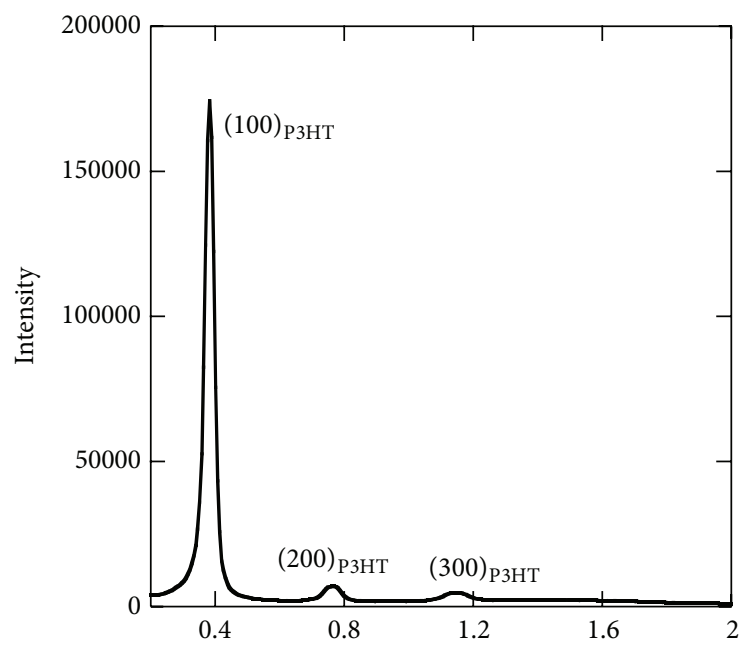

$q_{z}\left(\AA^{-1}\right)$

(e) Out-of-plane

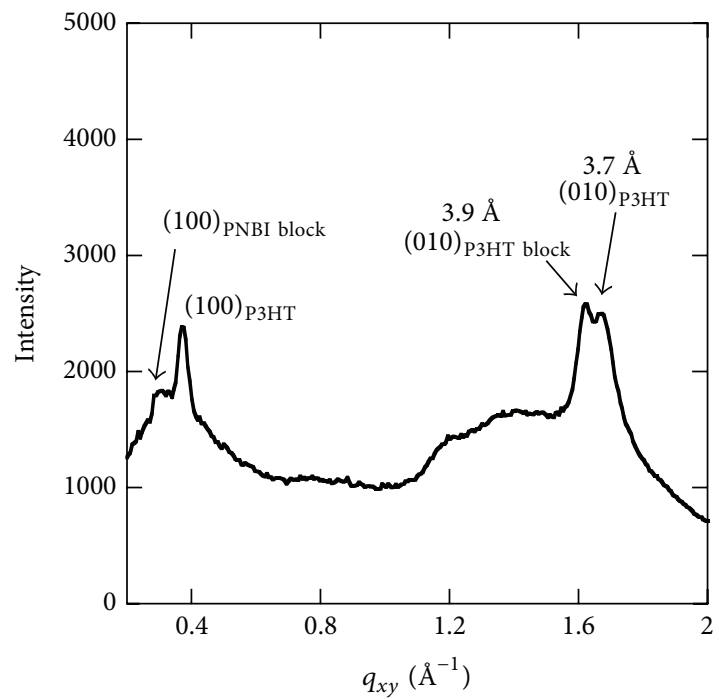

(f) In-plane

FIgURE 4: GIWAXS images and profiles of as-spun P3HT:P2 (a)-(c) and thermal annealed P3HT:P2 blend films (d)-(f). 
units compared to the P3HT:P3HT-PNBI-P3HT blend films; such large phase separation is not suitable for photoelectric conversion process because it brought about self-trapping of excitons, resulting in a low PCE. In the reported all-polymer solar cells using NBI-based polymers [29], the importance to prevent the self-aggregation was mentioned for minimizing self-trapping of excitons. It is likely that good miscibility of P3HT-PNBI-P3HT with P3HT provided the blend active layers which mixed well without self-aggregation of NBI units; this is major advantage of P3HT-PNBI-P3HT over other NBI-based polymers.

\subsection{Nanomorphology Observation by GIWAXS Measurement.} Next, GIWAXS measurements were carried out to investigate the in-depth study of the nanomorphology in the P3HT:P3HT-PNBI-P3HT blend films. The as-spun blend film exhibited the (h00) diffractions due to $\mathrm{P} 3 \mathrm{HT}$ in the $q_{z}$ axis (Figure $4(\mathrm{~b})$ ). In the $q_{x y}$ axis (Figure $4(\mathrm{c})$ ), three diffractions, which corresponded to the (100) diffraction due to P3HT (15.9 $\AA$ ), (100) diffraction due to PNBI blocks (20.3 $\AA$ ), and (010) diffraction (i.e., $\pi-\pi$ stacking) due to P3HT (3.7 $\AA$ ), were clearly observed. After thermal annealing at $200^{\circ} \mathrm{C}$, the stronger (h00) diffractions due to $\mathrm{P} 3 \mathrm{HT}$ were observed in the $q_{z}$ axis compared to the as-spun film (Figure 4(e)). In the $q_{x y}$ axis, two kinds of diffractions derived from $\pi-\pi$ stacking were observed at 3.9 and $3.7 \AA$ in addition to the (100) diffractions due to P3HT and PNBI (17.0 and 20.3 $\AA$, resp.). Given that the diffraction at $3.7 \AA$ is corresponding to $\pi-\pi$ stacking distance between P3HT homopolymers (Figure S3), the other diffraction at $3.9 \AA$ might correspond to $\pi-\pi$ stacking of P3HT blocks in P3HT-PNBI-P3HT. Furthermore, intensities of the diffractions due to $\mathrm{P} 3 \mathrm{HT}$ in the the $q_{z}$ axis and $\pi-\pi$ stacking in the $q_{x y}$ axis were clearly increased by thermal annealing, which suggested that thermal annealing triggered rearrangement of the polymer chains. Eventually, both P3HT homopolymers and P3HT blocks in P3HT-PNBI$\mathrm{P} 3 \mathrm{HT}$ were preferentially oriented in the edge-on manner whereas PNBI blocks were likely to orient in the face-on manner although the clear diffraction derived from $\pi-\pi$ stacking of PNBI blocks was not detected because of the low crystallinity. Quiet recently, the GIWAXS study of a similar fully conjugated diblock copolymer composed of PNBI and P3HT blocks was investigated by Wang et al. [30]. Although their block copolymer had the higher crystallinity than that of P3HT-PNBI-P3HT because of the less alkyl solubilized chains, no diffraction derived from $\pi-\pi$ stacking of PNBI blocks was observed. Face-on $\pi-\pi$ stacking of polymer chains is an ideal nanomorphology for the efficient photoelectric conversion process (e.g., efficient exciton diffusion and charge transportation). Indeed, several recent reports demonstrated the drastic improvements of PCEs were achieved by the faceon $\pi-\pi$ stacking nanomorphology in active layers compared to the devices with the edge-on nanomorphology [26-28]. Even though the P3HT:P3HT-PNBI-P3HT blend film had the nanomorphology rich in the edge-on orientation, enhanced polymer-polymer stacking in the thermal annealed film may attribute to the efficient photoelectric conversion process to give a high PCE of $1.60 \%$ compared to the as-spun film.

\section{Conclusions}

An all-polymer solar cell with a high PCE of $1.60 \%$ was successfully developed by using fully conjugated D-A block copolymers with NBI-based acceptor blocks (P3HT-PNBIP3HT) as a nonfullerene acceptor material. AFM and GIWAXS analyses demonstrated that the P3HT:P3HT-PNBI-P3HT blend film could form $\pi-\pi$ stacking nanomorphology without large aggregates, resulting in high device performance. This is the major advantage of P3HT-PNBI-P3HT because poor device performance caused by self-aggregation of NBIbased polymers in the blend film is a major problem in several all-polymer solar cells using NBI-based polymers. These results revealed the huge potential for the fully conjugated D-A block copolymer, P3HT-PNBI-P3HT, to be used as a nonfullerene acceptor material in OSCs, and we believe that further improvement of all-polymer solar cells based on P3HT-PNBI-P3HT is possible by fine-tuning of the chemical structure, more precise control of nanomorphology, device fabrication conditions, and so on.

\section{Conflict of Interests}

The authors declare that there is no conflict of interests regarding the publication of this paper.

\section{Acknowledgments}

This work is supported by Grant-in-Aid for Research Activity Start-up (23850004) provided by the Japan Society for the Promotion of Science (JSPS) and Inamori Foundation. The authors would like to thank Dr. Tomoaki Koganezawa for GIWAXS measurements.

\section{References}

[1] S. Günes, H. Neugebauer, and N. S. Sariciftci, "Conjugated polymer-based organic solar cells," Chemical Reviews, vol. 107, no. 4, pp. 1324-1338, 2007.

[2] B. C. Thompson and J. M. J. Fréchet, "Polymer-fullerene composite solar cells," Angewandte Chemie, vol. 47, no. 1, pp. 58-77, 2007.

[3] G. Dennler, M. C. Scharber, and C. J. Brabec, "Polymer-fullerene bulk-heterojunction solar cells," Advanced Materials, vol. 21, no. 13, pp. 1323-1338, 2009.

[4] H. Zhou, L. Yang, and W. You, "Rational design of high performance conjugated polymers for organic solar cells," Macromolecules, vol. 45, no. 2, pp. 607-632, 2012.

[5] J. You, L. Dou, K. Yoshimura et al., "A polymer tandem solar cell with $10.6 \%$ power conversion efficiency," Nature Communications, vol. 4, article 1446, 2013.

[6] V. D. Mihailetchi, J. K. J. Van Duren, P. W. M. Blom et al., "Electron transport in a methanofullerene," Advanced Functional Materials, vol. 13, no. 1, pp. 43-46, 2003.

[7] A. Facchetti, "Polymer donor-polymer acceptor (all-polymer) solar cells," Materials Today, vol. 16, no. 4, pp. 123-132, 2013.

[8] J. Wang and T. Higashihara, "Synthesis of all-conjugated donoracceptor block copolymers and their application in all-polymer solar cells," Polymer Chemistry, vol. 4, no. 22, pp. 5518-5526, 2013. 
[9] D. Mori, H. Benten, H. Ohkita, S. Ito, and K. Miyake, "Polymer/polymer blend solar cells improved by using high-molecular-weight fluorene-based copolymer as electron acceptor," ACS Applied Materials and Interfaces, vol. 4, no. 7, pp. 3325-3329, 2012.

[10] E. Zhou, K. Tajima, C. Yang, and K. Hashimoto, "Band gap and molecular energy level control of perylene diimide-based donor-acceptor copolymers for all-polymer solar cells," Journal of Materials Chemistry, vol. 20, no. 12, pp. 2362-2368, 2010.

[11] N. Zhou, H. Lin, S. J. Lou et al., "Morphology-performance relationships in high-efficiency all-polymer solar cells," Advanced Energy Materials, vol. 4, no. 3, Article ID 1300785, 2014.

[12] D. Mori, H. Benten, I. Okada, H. Ohkita, and S. Ito, "Lowbandgap donor/acceptor polymer blend solar cells with efficiency exceeding 4\%," Advanced Energy Materials, vol. 4, no. 3, Article ID 1301006, 2014.

[13] S. Fabiano, Z. Chen, S. Vahedi, A. Facchetti, B. Pignataro, and M. A. Loi, "Role of photoactive layer morphology in high fill factor all-polymer bulk heterojunction solar cells," Journal of Materials Chemistry, vol. 21, no. 16, pp. 5891-5896, 2011.

[14] Y. Kim, S. Cook, S. A. Choulis, J. Nelson, J. R. Durrant, and D. D. C. Bradley, "Organic photovoltaic devices based on blends of regioregular poly(3-hexylthiophene) and poly(9,9-dioctylfluorene-co-benzothiadiazole)," Chemistry of Materials, vol. 16, no. 23, pp. 4812-4818, 2004.

[15] H. J. Snaith, A. C. Arias, A. C. Morteani, C. Silva, and R. H. Friend, "Charge generation kinetics and transport mechanisms in blended polyfluorene photovoltaic devices," Nano Letters, vol. 2, no. 12, pp. 1353-1357, 2002.

[16] K. Nakabayashi and H. Mori, "All-polymer solar cells based on fully conjugated block copolymers composed of poly(3hexylthiophene) and poly(naphthalene bisimide) segments," Macromolecules, vol. 45, no. 24, pp. 9618-9625, 2012.

[17] M. Yuan, M. M. Durban, P. D. Kazarinoff et al., "Synthesis and characterization of fused-thiophene containing naphthalene diimide n-type copolymers for organic thin film transistor and all-polymer solar cell applications," Journal of Polymer Science, Part A: Polymer Chemistry, vol. 51, no. 19, pp. 4061-4069, 2013.

[18] M. Schubert, D. Dolfen, J. Frisch et al., "Influence of aggregation on the performance of all-polymer solar cells containing lowbandgap naphthalenediimide copolymers," Advanced Energy Materials, vol. 2, no. 3, pp. 369-380, 2012.

[19] Y.-J. Hwang, G. Ren, N. M. Murari, and S. A. Jenekhe, "N-type naphthalene diimide-biselenophene copolymer for all-polymer bulk heterojunction solar cells," Macromolecules, vol. 45, no. 22, pp. 9056-9062, 2012.

[20] E. Zhou, J. Cong, J. Q. Wei, K. Tajima, C. Yang, and K. Hashimoto, "All-polymer solar cells from perylene diimide based copolymers: material design and phase separation control," Angewandte Chemie, vol. 123, pp. 2851-2855, 2011.

[21] X. Zhang, Z. Lu, L. Ye et al., "A potential perylene diimide dimer-based acceptor material for highly efficient solutionprocessed non-fullerene organic solar cells with $4.03 \%$ efficiency," Advanced Materials, vol. 25, no. 40, pp. 5791-5797, 2013.

[22] N. Zhou, H. Lin, S. J. Lou et al., "Morphology-performance relationships in high-efficiency all-polymer solar cells," Advanced Energy Materials, vol. 4, no. 3, Article ID 1300785, 2014.

[23] T. Earmme, Y.-J. Hwang, N. M. Murari, S. Subramaniyan, and S. A. Jenekhe, "All-polymer solar cells with 3.3\% efficiency based on naphthalene diimide-selenophene copolymer acceptor," Journal of the American Chemical Society, vol. 135, no. 40, pp. 14960-14963, 2013.
[24] D. Mori, H. Benten, J. Kosaka, H. Ohkita, S. Ito, and K. Miyake, "Polymer/polymer blend solar cells with $2.0 \%$ efficiency developed by thermal purification of nanoscale-phase-separated morphology," ACS Applied Materials and Interfaces, vol. 3, no. 8, pp. 2924-2927, 2011.

[25] E. Verploegen, R. Mondal, C. J. Bettinger, S. Sok, M. F. Toney, and Z. Bao, "Effects of thermal annealing upon the morphology of polymer-fullerene blends," Advanced Functional Materials, vol. 20, no. 20, pp. 3519-3529, 2010.

[26] I. Osaka, T. Kakara, N. Takemura, T. Koganezawa, and K. Takimiya, "Naphthodithiophene-naphthobisthiadiazole copolymers for solar cells: alkylation drives the polymer backbone flat and promotes efficiency," Journal of the American Chemical Society, vol. 135, no. 24, pp. 8834-8837, 2013.

[27] I. Osaka, M. Shimawaki, H. Mori et al., "Synthesis, characterization, and transistor and solar cell applications of a naphthobisthiadiazole-based semiconducting polymer," Journal of the American Chemical Society, vol. 134, no. 7, pp. 3498-3507, 2012.

[28] M. S. Chen, J. R. Niskala, D. A. Unruh, C. K. Chu, O. P. Lee, and J. M. J. Fréchet, "Control of polymer-packing orientation in thin films through synthetic tailoring of backbone coplanarity," Chemistry of Materials, vol. 25, no. 20, pp. 4088-4096, 2013.

[29] J. R. Moore, S. Albert-Seifried, A. Rao et al., "Polymer blend solar cells based on a high-mobility naphthalenediimide-based polymer acceptor: device physics, photophysics and morphology," Advanced Energy Materials, vol. 1, no. 2, pp. 230-240, 2011.

[30] J. Wang, M. Ueda, and T. Higashihara, "Synthesis and morphology of all-conjugated donor-acceptor block copolymers based on poly(3-hexylthiophene) and poly(naphthalene diimide)," Journal of Polymer Science, Part A: Polymer Chemistry, vol. 52, no. 8, pp. 1139-1148, 2014. 

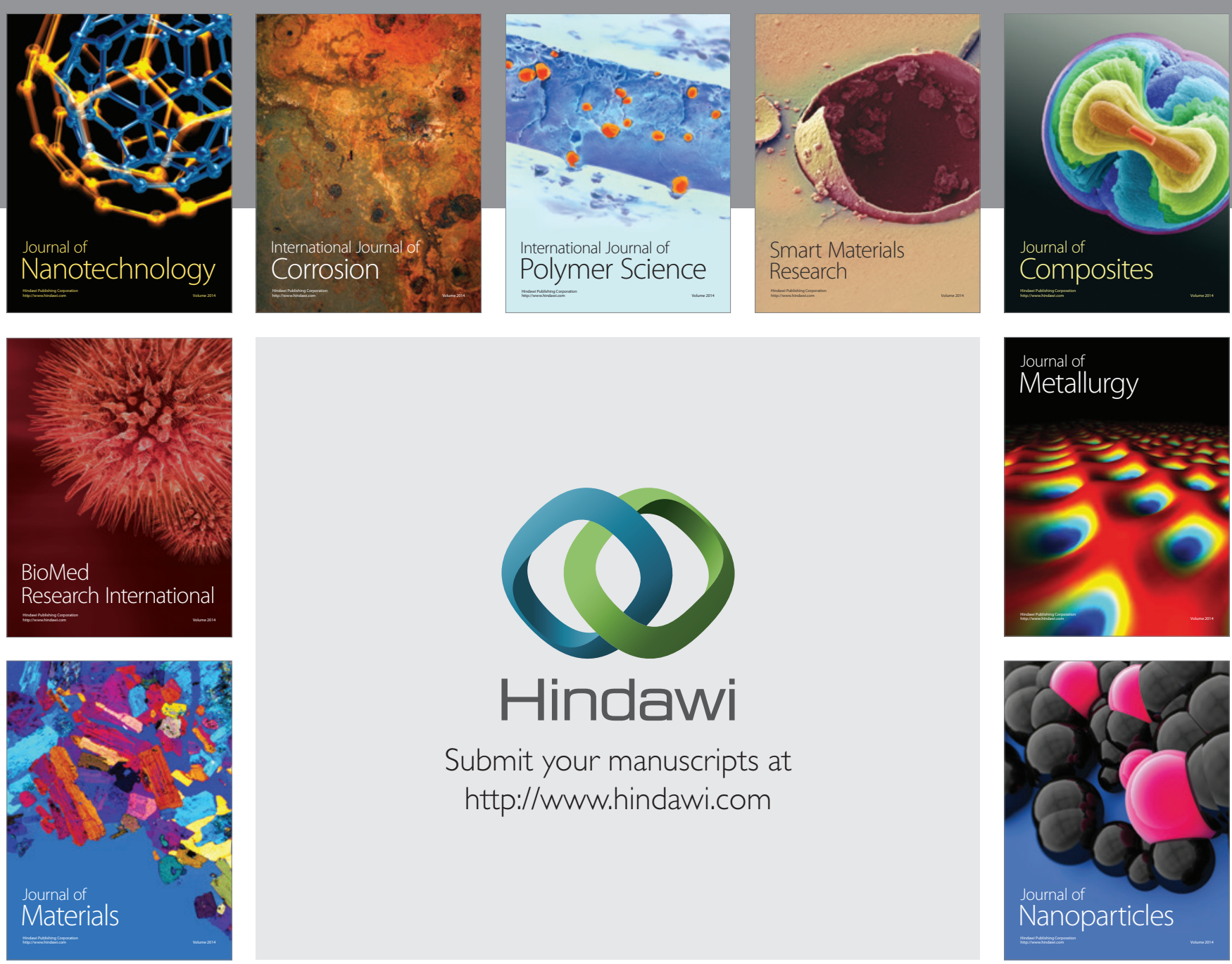

Submit your manuscripts at http://www.hindawi.com
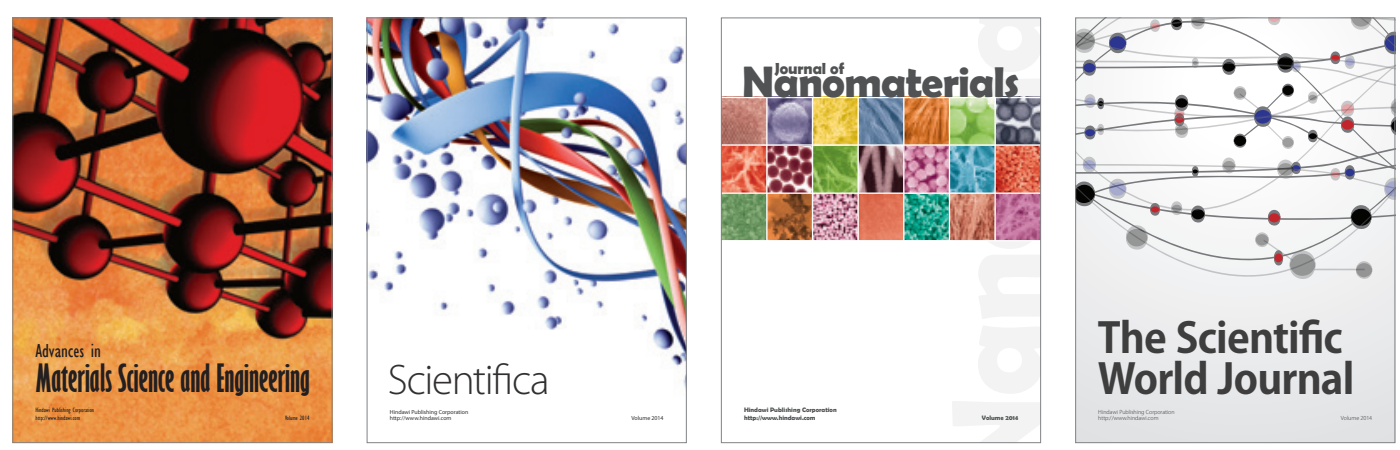

\section{The Scientific World Journal}
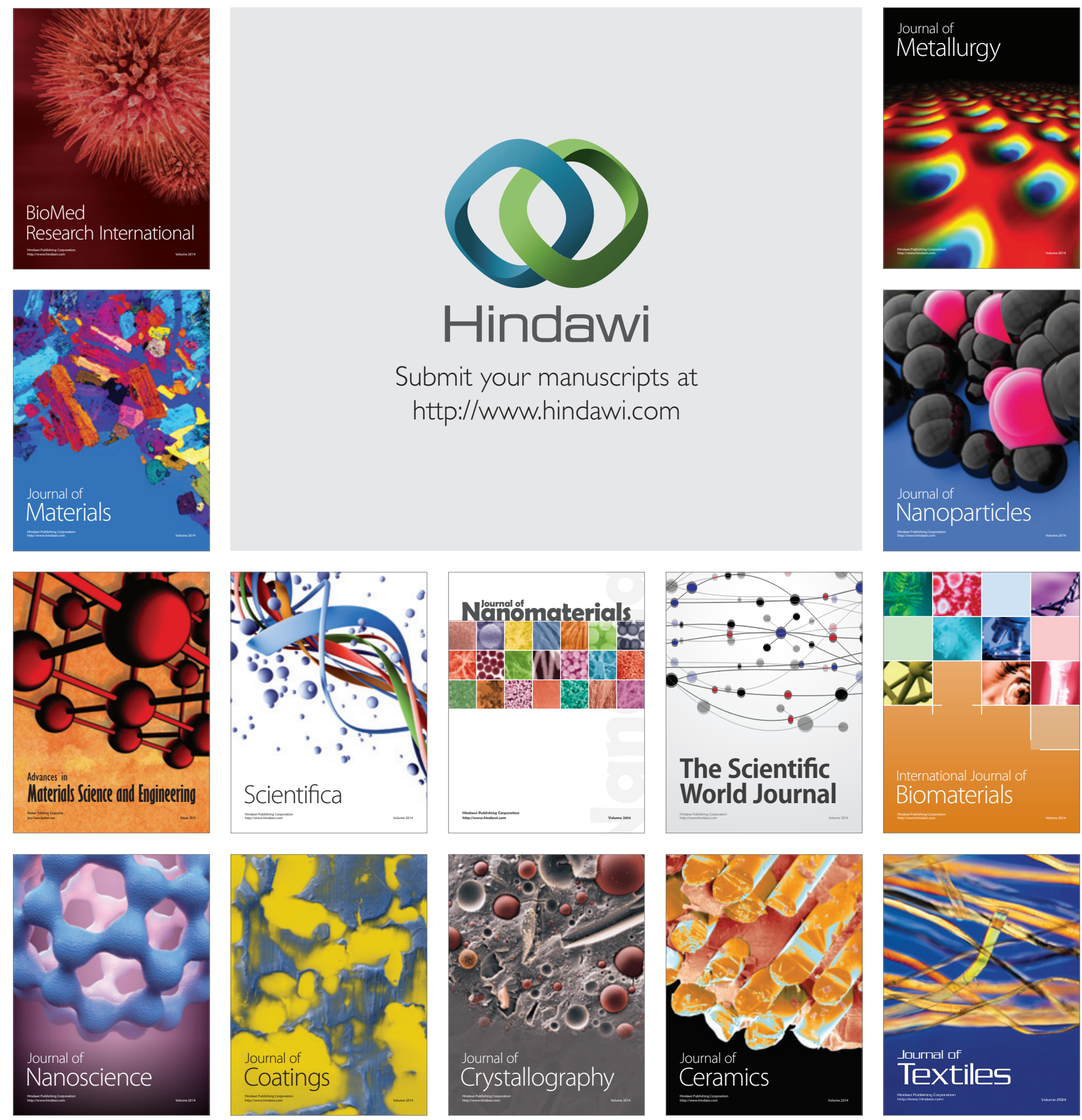